\title{
Consumer perception, health information, and instrumental parameters of cupuassu (Theobroma grandiflorum) goat milk yogurts
}

\author{
Marion P. Costa, ${ }^{*}{ }^{1}$ Maria Lucia G. Monteiro, ${ }^{*}$ Beatriz S. Frasao, ${ }^{*}$ Vitor L. M. Silva, ${ }^{*}$ Bruna L. Rodrigues, ${ }^{*}$ \\ Claudete C. J. Chiappini, $\ddagger$ and Carlos A. Conte-Junior ${ }^{*} †$ \\ *Departamento de Tecnologia Alimentos, Universidade Federal Fluminense, 24230-340, Niterói, Rio de Janeiro, Brazil \\ †Food Science Program, Instituto de Química, Universidade Federal do Rio de Janeiro, 21941-909, Rio de Janeiro, Brazil \\ ‡Departamento de Alimento e Nutrição, Universidade Federal Fluminense, 24020-140, Niterói, Rio de Janeiro, Brazil
}

\section{ABSTRACT}

Although the demand for goat milk products has been growing, they have lower consumer acceptability than products derived from cow milk. However, the addition of cupuassu pulp can be used to improve the formulation of these products. For this reason, the aim of this study was to investigate the influence of new goat milk yogurt manufactured with cupuassu pulp on physicochemical properties, consumers' perceptions, and overall consumer acceptance. In addition, the effect of antioxidant health information on consumer acceptance and purchase intention of cupuassu goat milk yogurts was evaluated. The results demonstrated a positive expectation regarding linking and familiarity to goat milk products and products with cupuassu pulp. The $\mathrm{pH}$, total phenolic content, lightness, redness, yellowness, and apparent viscosity were potentially affected by the addition of cupuassu, with the highest concentration of cupuassu $(10 \%)$ exhibiting the greatest changes in parameters. Based on principal component analysis, partial least squares regression, and just-about-right and penalty analysis, the addition of cupuassu pulp improved some sensory attributes of goat milk yogurt, such as cupuassu aroma, cupuassu flavor, yellow color, consistency, and viscosity, which positively influenced product acceptance. In addition, antioxidant health information increased the acceptance and purchase intention of cupuassu goat milk yogurts. Taking into account the parameters investigated in this study, the best scoring formulation was goat milk yogurt with $10 \%$ cupuassu pulp. Our results suggest that cupuassu pulp can be considered a potential ingredient to improve the sensory and texture properties of goat milk yogurt. Furthermore, the antioxidant health information could be a sensory strategy to increase the acceptance of cupuassu goat milk yogurts.

Received April 13, 2016.

Accepted September 8, 2016.

${ }^{1}$ Corresponding author: marioncosta@id.uff.br
Key words: novel product, instrumental analysis, health claims, expected liking

\section{INTRODUCTION}

The functional dairy market has been increasing due to high demand from health-conscious consumers interested in products with basic nutritional function and physiological benefits such as decreasing the risk of chronic disease (Kraus, 2015). In this current scenario, the dairy industry, therefore, faces great challenges such as developing of innovative products with useful functional properties, meeting consumers' health demands, and maintaining their place in a competitive market (Costa et al., 2013; Khan et al., 2013). In addition, the demand for goat milk products has been growing due to problems with allergies to cow milk (Ribeiro and Ribeiro, 2010; Costa and Conte-Junior, 2013). However, goat milk yogurt has a low acceptability compared with cow milk yogurt (Costa et al., 2015a) and is not well accepted by nonhabitual consumers (Costa et al., 2014). Moreover, goat milk yogurt has a weak curd due to a lack of $\alpha_{\mathrm{S} 1}$ casein, which makes it difficult to manufacture goat milk yogurt with the appropriate texture. However, according to Costa et al. (2015b), the addition of cupuassu pulp to goat milk yogurt can improve the instrumental texture and could be an important technological strategy for the dairy goat industry.

Cupuassu is a Brazilian Amazonian fruit belonging to the same family (Sterculiaceae) as cacao (Theobroma cacao). This fruit is mainly used as an ingredient in producing ice cream, juice, liquors, and jellies because of its distinctive flavor. Cupuassu is composed of a large proportion of starch, pectin polysaccharides (Vriesmann et al., 2009), and dietary fiber, mainly in the form of insoluble fiber (Salgado et al., 2011), which improves the texture parameters of dairy products relative to other ingredients, such as inulin (Costa et al., 2015b). Furthermore, cupuassu pulp contains high ascorbic acid and total phenolic contents, resulting in greater antioxidant activity when compared with fruit pulps that 
are more commonly used for yogurt production, such as strawberry pulp (Silva Pinto et al., 2008; Pugliese et al., 2013). Moreover, cupuassu is a natural source of antioxidants, which have been widely studied because of the real or perceived effects of synthetic antioxidants on human health (Lobo et al., 2010).

Antioxidant consumption has been associated with decreased levels of oxidative damage to lymphocytic DNA, and can minimize the risks for pathologies induced by an oxidative stress such as cancer, Alzheimer's and Parkinson's diseases (Zhao, 2009). In addition, some studies have reported that information about nutrition and health claims may have a positive influence on the decisions of consumers and can improve the overall acceptability and purchase intention of several products such as yogurts, milk, and vanilla soybean beverages (Villegas et al., 2008; Lampila et al., 2009; Vidigal et al., 2011; Fernqvist and Ekelund, 2014). In this context, the aim of the present study was to investigate the consumer perceptions of a new product based on goat milk yogurt and cupuassu pulp. The better percentage of cupuassu pulp addition was determined by sensory and physicochemical analyses. Finally, it was determined if health claims could enhance consumer acceptance and purchase intention for cupuassu goat milk yogurts.

\section{MATERIALS AND METHODS}

\section{Study Design}

The sensory evaluation consisted of 3 stages (Figure 1). First, the predictions of expected liking and expected familiarity using a questionnaire (no consumption) were evaluated. Second, the better percentage of cupuassu pulp in goat milk yogurt was selected by overall acceptability, purchase intention, and just-about-right (JAR) scaling. Physicochemical parameters were analyzed to correlate with sensory data. Finally, the effect of antioxidant health information (blind and informed groups) on overall acceptability, cupuassu flavor, and purchase intention for the cupuassu goat milk yogurts was determined. The yogurt manufacturing process was identical for all stages, which were presented in randomized blocks in a sequential monadic way. Physicochemical analyses $(\mathrm{pH}$, total phenolic content, instrumental color, apparent viscosity, and texture) were performed in all yogurt preparations $(\mathrm{n}=2)$.

\section{Treatment}

Twenty-three liters of goat milk yogurt was produced as described by Costa et al. (2015b). For all treatments, thermophilic yogurt cultures (1\% vol/vol; YF-L903; Chr. Hansen, Valinhos, Brazil), sugar (3\% wt/vol), and cupuassu pulp (0-10\% wt/vol) were added into UHT goat whole milk (86-96\% vol/vol; Cappry's, Rio Grande do Sul, Brazil). A total of 4 treatments were performed: natural (NY), 5\% cupuassu pulp (CY5), 7.5\% cupuassu pulp (CY7.5), and $10 \%$ cupuassu pulp (CY10). The yogurt mixtures were fermented in an oven at $43 \pm 2^{\circ} \mathrm{C}$. The fermentation was interrupted by chilling when the $\mathrm{pH}$ (AOAC International, 2012) reached 4.6. Finally, the product was packaged in 2,000$\mathrm{mL}$ glass pots and stored at $4 \pm 2{ }^{\circ} \mathrm{C}$ until analysis.

\section{Consumer Testing}

For the questionnaire session, participants were randomly recruited, using no specific criteria to select them. For the food tasting sessions, all participants provided written informed consent. In this case, they were selected by their frequency of yogurt consumption (at least once a week), and as nonsensitive consumers (individuals free of lactose intolerance and allergies to milk and its derivatives). All participants were recruited from the Food Science and Technology Department and the Nutrition Department (Universidade Federal Fluminense, Brazil).

Samples $(20 \mathrm{~mL})$ were served individually in a monadic sequential order using a balanced block design in standard sensory booths. All samples were served in plastic containers $\left(35 \mathrm{~mm}\right.$ diameter) at $8^{\circ} \mathrm{C}$ and coded with random 3-digit codes. For sensory evaluation of aroma, all samples were served with lids closed and participants were instructed to remove the lid only at the moment of aroma analysis to minimize the loss of volatiles. Cream crackers without salt and filtered water at controlled room temperature $\left(25^{\circ} \mathrm{C}\right)$ were used to cleanse the palate between samples.

\section{Consumer Expectations}

This test was carried out according to Costa et al. (2014) with modifications. Participants ( $\mathrm{n}=300 ; 228$ women, $72 \mathrm{men}$ ) with ages ranging from 18 to $65 \mathrm{yr}$ old $($ mean $=26, \mathrm{SD}=6$ ) were instructed to answer a questionnaire about expected liking and expected familiarity regarding goat milk yogurt, cupuassu pulp, and the specific product (cupuassu goat milk yogurt). This study was performed over 2 wk. Consumers who infrequently eat yogurt (i.e., at least once per week) were excluded from the sensory test. Three questions were used to score participants' expectations regarding product acceptance:

(i) What is your expected liking about the flavor of goat milk products? 
(ii) What is your expected liking about the flavor of cupuassu pulp?

(iii) What is your expected liking about the flavor of goat milk yogurt with cupuassu pulp added?

These questions were answered on a 9-point category scale $(1=$ would extremely dislike to $9=$ would extremely like). In addition, participants rated their expected familiarity on a 9-point scale anchored at both extremes $(1=$ not at all familiar to $9=$ extremely familiar) by using 2 questions:

(i) What is your familiarity with goat milk products?

(ii) What is your familiarity with products containing cupuassu pulp?

\section{Sensory and Physicochemical Analyses}

The sensory tests were assessed by overall acceptability, purchase intention, and JAR scaling. In addition, physicochemical analyses $(\mathrm{pH}$, total phenolic content, instrumental color, apparent viscosity, and texture) were conducted to correlate them with sensory data.

Acceptance Test and Purchase Intention. Test sessions were performed over 2 wk. One hundred sixty participants (122 women, 38 men) ranging from 19 to $63 \mathrm{yr}$ old $($ mean $=26, \mathrm{SD}=7)$ were recruited.

The participants evaluated appearance, color, aroma, flavor, texture, and overall acceptability of each sample based on a 9 -point category scale $(1=$ extremely dislike to 9 = extremely like). Additionally, aroma (acid, alcoholic, caprine, and cupuassu), taste (sweet and acid),
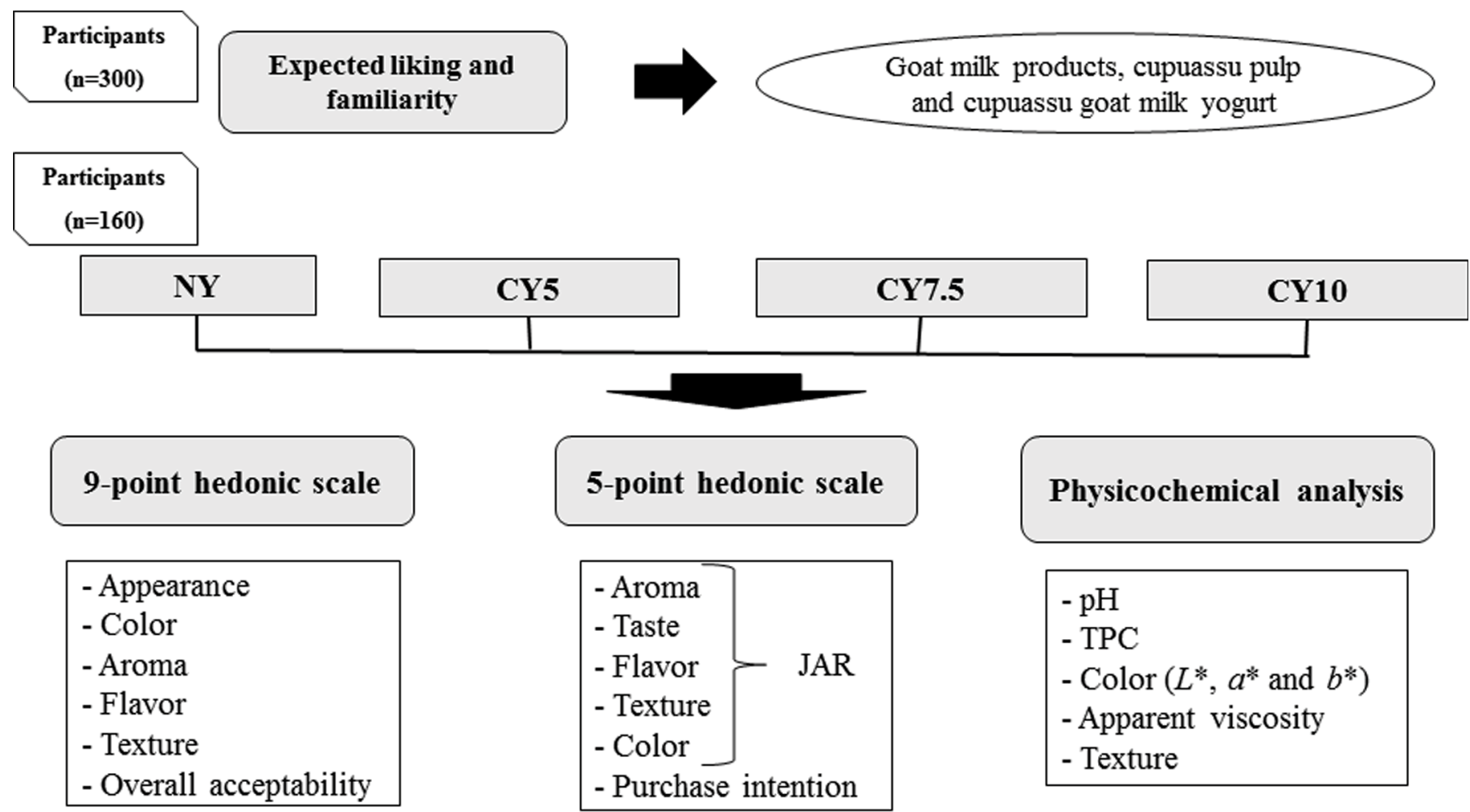

\section{5-point hedonic scale}

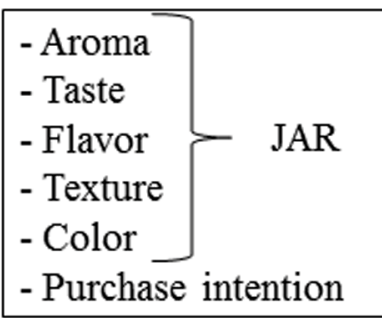

\section{Physicochemical analysis}

$-\mathrm{pH}$

- TPC

- Color $\left(L^{*}, a^{*}\right.$ and $\left.b^{*}\right)$

- Apparent viscosity

- Texture

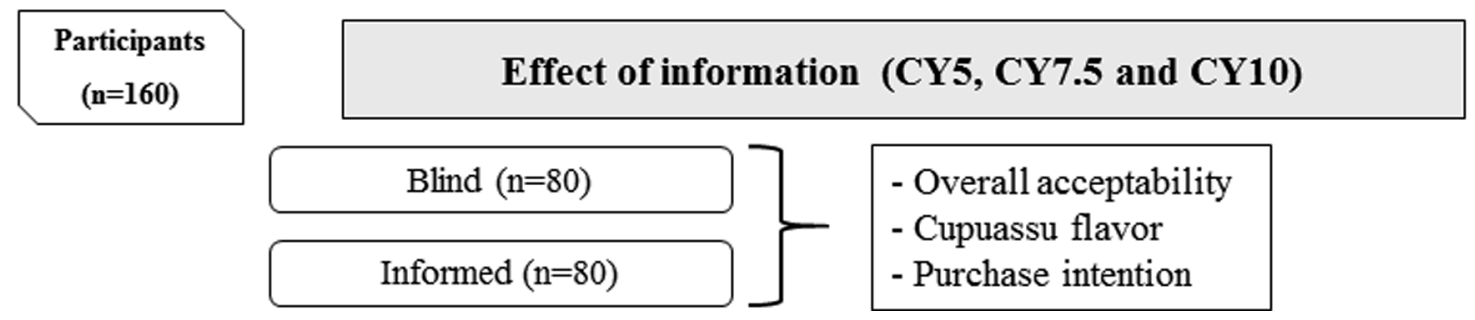

Figure 1. Study design illustrating the stages involved in the experiment. NY = natural goat milk yogurt; CY5 = cupuassu goat milk yogurt with $5.0 \%$ pulp; CY7.5 = cupuassu goat milk yogurt with $7.5 \%$ pulp; CY10 = cupuassu goat milk yogurt with $10.0 \%$ pulp; TPC $=$ total phenolics content; $L^{*}=$ lightness; $a^{*}=$ redness; and $b^{*}=$ yellowness; JAR $=$ just about right. 
flavor (caprine and cupuassu), color (white and yellow), and texture (consistency and viscosity) were evaluated using a 5-point JAR scale anchored at both extremes (1 $=$ not enough to $5=$ too much), with a central point at 3 (ideal; Li et al., 2014). Participants also scored their purchase intention on a 5 -point scale ranging from $1=$ certainly wouldn't buy to $5=$ certainly would buy.

Physicochemical Analyses. Physicochemical analyses were performed in triplicate.

The $\mathrm{pH}$ values were measured according to AOAC methods (AOAC International, 2012), using a digital pH meter model PG1800 (Cap Lab, São Paulo, Brazil). The total phenolics content (TPC) was performed using the Folin-Ciocalteu method (Singleton and Rossi, 1965).

Instrumental color parameters were determined by reflectance using a Minolta CM-600D Spectrophotometer (Minolta Camera Co., Osaka, Japan) calibrated with illuminant D65 and a $2^{\circ}$ standard observer (Costa et al., 2015b). Yogurt samples $(50 \mathrm{~mL})$ at $5^{\circ} \mathrm{C}$ were stirred and poured into an aluminum cylinder $(55 \mathrm{~mm}$ outside diameter), with the surface optically flattened and the sensor mounted directly on the top of the cylinder to avoid stray light. The $\mathrm{L}^{*}$ (from black to white, 0-100), $\mathrm{a}^{*}$ (from green to red, $-\mathrm{a}^{*}$ to $+\mathrm{a}^{*}$ ), and $\mathrm{b}^{*}$ (from blue to yellow, $-b^{*}$ to $\left.+b^{*}\right)$ values were determined.

For apparent viscosity analysis, yogurt samples (300 $\mathrm{mL})$ were analyzed $\left(5^{\circ} \mathrm{C}\right)$ using a Brookfield concentric cylinder viscometer (DV3T, Brookfield Engineering Laboratories Inc., Stoughton, MA) equipped with rotor no. 63 and a speed of $60 \mathrm{rpm}$ (Costa et al., 2015b). The results were expressed in $\mathrm{mPa} \cdot \mathrm{s}$.

Texture analysis was performed according to Costa et al. (2015b) using a TA.XT plus texture analyzer (Stable Micro Systems Ltd., Surrey, UK) equipped with a $5 \mathrm{~kg} \cdot f$ load cell. The texture parameters analyzed were firmness, consistency, and cohesiveness. The samples (100 $\mathrm{mL}$ ) were compressed by $10 \%$ of original height with a back extrusion cell (A/BE) disc (36 mm diameter; $30 \mathrm{~mm}$ distance; $1 \mathrm{~mm} \cdot \mathrm{s}^{-1}$ speed) under temperaturecontrolled conditions $\left(5^{\circ} \mathrm{C}\right)$. The assays were carried out in a $50 \mathrm{~mm}$ diameter standard size back extrusion container, and the disc was placed in a central position over the sample container.

\section{Effect of Health Information}

The effect of health information test was carried out over 2 d. Participants $(\mathrm{n}=160,90$ women, 70 men) ranging from 19 to $60 \mathrm{yr}$ old $($ mean $=28.85, \mathrm{SD}=$ 8.62 ) were divided into 2 groups to evaluate the effect of health information on the overall acceptability (9-point scale ranging from $1=$ extremely dislike to 9
$=$ extremely like), cupuassu flavor (9-point scale ranging from 1 = extremely dislike to $9=$ extremely like), and purchase intention (5-point scale ranging from $1=$ certainly would not buy to $5=$ certainly would buy) of the cupuassu goat milk yogurts (CY5, CY7.5, and CY10). A dummy sample was served as the first sample to participants with the aim of eliminating the first sample effect (Lawless and Heymann, 2010). This sample contained an identical volume of each sample (CY5, CY7.5, and CY10). The results from the dummy sample were not considered in the statistical analyses (Kim and Hong 2015). Eighty participants received the samples without any information (blind group), and the following information was provided to the other 80 participants (informed group):

"You will taste a new health yogurt, which was prepared with goat milk and cupuassu pulp. The cupuassu pulp contains high ascorbic acid levels and phenolic contents, which are natural antioxidant compounds. The consumption of both ascorbic acid and phenolic compounds is associated with beneficial health effects such as delayed aging and the prevention of degenerative pathologies i.e., Alzheimer's disease."

After testing, a question ("Why is the consumption of antioxidants important?") was asked to ensure that participants had read the information provided. The results from participants who provided a wrong response or did not answer were not used for any data analyses.

\section{Statistical Analyses}

Physicochemical parameters $(\mathrm{pH}$, total phenolic content, instrumental color, apparent viscosity, and texture) as well as sensory parameters (acceptance, JAR, purchase intention, and health information) were analyzed by one-way ANOVA with post hoc Tukey tests at the $95 \%$ confidence level $(P<0.05)$. For sensory data, treatments were considered as a fixed source of variation and the consumer as a random effect. Principal component analysis (PCA) was performed to visualize the parameters that were affected by the cupuassu pulp. Partial least squares regression (PLSR) was used to verify if the determinant parameters contributed positively or negatively to the overall acceptability of the cupuassu yogurts made from goat milk. Penalty analysis was carried out on JAR data to identify decreases in the overall acceptability where consumers rated the attributes at "not enough" or "too much." Pearson correlation was performed to correlate the physicochemical and sensory data $(P<0.05)$. All statistical analyses were performed using XLSTAT version 2012.6.08 software (Addinsoft, Paris, France). 
Table 1. Mean liking scores for the different formulations of cupuassu yogurts made from goat milk ${ }^{1}$

\begin{tabular}{|c|c|c|c|c|c|c|c|}
\hline Treatment & \multicolumn{7}{|c|}{ Attribute } \\
\hline CY5 & $6.47 \pm 1.73^{\mathrm{a}}$ & $7.02 \pm 1.49^{\mathrm{a}}$ & $6.13 \pm 1.93^{\mathrm{a}}$ & $4.72 \pm 2.26^{\mathrm{a}}$ & $5.26 \pm 2.04^{\mathrm{a}}$ & $4.90 \pm 2.09^{\mathrm{a}}$ & $2.40 \pm 1.18^{\mathrm{a}}$ \\
\hline CY7.5 & $6.27 \pm 1.80^{\mathrm{a}}$ & $6.73 \pm 1.61^{\mathrm{a}}$ & $6.14 \pm 2.10^{\mathrm{a}}$ & $4.80 \pm 2.50^{\mathrm{a}}$ & $5.37 \pm 2.14^{\mathrm{a}}$ & $5.03 \pm 2.28^{\mathrm{a}}$ & $2.49 \pm 1.23^{\mathrm{a}}$ \\
\hline CY10 & $6.46 \pm 1.81^{\mathrm{a}}$ & $6.86 \pm 1.46^{\mathrm{a}}$ & $6.17 \pm 2.21^{\mathrm{a}}$ & $4.77 \pm 2.35^{\mathrm{a}}$ & $5.42 \pm 1.96^{\mathrm{a}}$ & $5.09 \pm 2.17^{\mathrm{a}}$ & $2.55 \pm 1.19^{\mathrm{a}}$ \\
\hline
\end{tabular}

${ }^{\mathrm{a}}$ Different lowercase letters in the same column represent significant differences $(P<0.05)$.

${ }^{1}$ Purchase intention was evaluated in a structured 5-point hedonic scale, whereas the other attributes were evaluated on a 9-point hedonic scale. $\mathrm{NY}=$ natural goat milk yogurt; CY5 = cupuassu goat milk yogurt with $5.0 \%$ pulp; CY7.5 = cupuassu goat milk yogurt with $7.5 \%$ pulp; CY10 $=$ cupuassu goat milk yogurt with $10.0 \%$ pulp. Values were expressed as a mean \pm SD.

\section{RESULTS AND DISCUSSION}

\section{Expected Liking and Expected Familiarity}

Regarding expected liking, most of the responses scored between "would like slightly" and "would like very much" (6-8) totaling 65, 67, and $69 \%$ for goat milk products, cupuassu pulp, and cupuassu goat milk yogurt, respectively. However, the expected liking $\left[\mathrm{F}_{(0.10)}=53.220 ; P<0.001\right]$ related to cupuassu pulp flavor $(4.60 \pm 2.29)$ was lower than the expected liking concerning goat milk products $(6.05 \pm 1.87)$ and cupuassu goat milk yogurt flavor $(5.99 \pm 1.75)$. For food consumption, a positive expectation plays an important role, suggesting that it can improve the perception of a new product, even before it is tasted.

The expected familiarity for goat milk products was rated between "neither would like nor would dislike" to "would like moderately" (5-7) by $48 \%$ of the participants, whereas $57 \%$ of the participants scored the expected familiarity between "slightly familiar" and "very much familiar" (6-8) for products containing cupuassu pulp. Regarding mean values, the participants demonstrated greater familiarity $\left[\mathrm{F}_{(0.04)}=27.775, P<\right.$ 0.001] with products containing cupuassu pulp (6.46 $\pm 1.84)$ than with goat milk products $(5.60 \pm 2.23)$. Hong et al. (2014) suggested that different levels of product familiarity strongly influence the perception of traditional products by consumers, which can or can not be positive for a new product. These results indicate that most of the participants exhibited a positive expectation for both expected liking and expected familiarity with respect to goat milk products. In addition, for expected familiarity, consumers were more familiar with products containing cupuassu pulp than with goat milk products. This result may be related to the higher expectations for derivatives from goat milk, which was unexpected. This fact is important because the relationship between expectations and real sensory perception is likely to be very critical in the case of a novel product (Tuorila et al., 1998).
Despite the low score on the expected liking of cupuassu pulp flavor and less familiarity with goat milk products, no influence was observed in the acceptance of cupuassu goat milk yogurt (CY5, CY7.5, and CY10), indicating the potential of using cupuassu pulp as a functional ingredient in products derived from goat milk.

\section{Acceptance Test, Purchase Intention, JAR Profile, and Penalty Analysis}

No difference $(P>0.05)$ was observed in appearance, color, aroma, flavor, texture, overall acceptability, or purchase intention for all treatments (Table 1). Nevertheless, appearance, color, and aroma attributes were positively scored. Appearance and color were rated between "like slightly" and "like moderately" (6-7), whereas aroma was scored between "neither like" nor "dislike and like slightly" (5-6).

For purchase intention (Table 1), all treatments were rated between "probably would not buy" and "may/ may not buy" (2-3). Despite the low score on the expected liking of cupuassu pulp flavor and less familiarity with goat milk products, no influence was observed in the acceptance and purchase intention of cupuassu goat milk yogurt (CY5, CY7.5, and CY10), indicating the potential of using cupuassu pulp as a functional ingredient in products derived from goat milk.

The responses for the JAR questions on a 5-point hedonic scale are presented in Table 2. No difference $(P>0.05)$ was observed in the caprine aroma, white color, acid, and sweet taste. In general, the increasing cupuassu content resulted in a greater perception of acid, alcoholic and cupuassu aroma, cupuassu flavor, yellow color, consistency, and viscosity. In addition, cupuassu pulp (at 10\%) decreased the perception of caprine flavor in yogurt, which would be favorable to nonhabitual consumers. Penalty analysis was used with JAR scores to identify a potential formulation for the improvement of goat milk yogurt aimed at increasing 
Table 2. Just-about-right (JAR) profile scores for the different formulations evaluated ${ }^{1}$

\begin{tabular}{|c|c|c|c|c|}
\hline \multirow[b]{2}{*}{ Treatment } & \multicolumn{4}{|c|}{ Aroma } \\
\hline & Acid & Alcoholic & Caprine & Cupuassu \\
\hline$\overline{\mathrm{NY}}$ & $3.08 \pm 0.85^{\mathrm{b}}$ & $2.89 \pm 0.76^{\mathrm{b}}$ & $3.19 \pm 0.84^{\mathrm{a}}$ & $2.33 \pm 0.91^{\mathrm{b}}$ \\
\hline CY5 & $3.41 \pm 0.80^{\mathrm{a}}$ & $3.30 \pm 0.87^{\mathrm{a}}$ & $3.14 \pm 1.05^{\mathrm{a}}$ & $2.73 \pm 1.01^{\mathrm{a}}$ \\
\hline CY7.5 & $3.34 \pm 0.80^{\mathrm{a}}$ & $3.24 \pm 0.84^{\mathrm{a}}$ & $3.08 \pm 0.93^{\mathrm{a}}$ & $2.82 \pm 0.96^{\mathrm{a}}$ \\
\hline \multirow[t]{3}{*}{ CY10 } & $3.32 \pm 0.86^{\mathrm{ab}}$ & $3.28 \pm 0.91^{\mathrm{a}}$ & $3.07 \pm 0.99^{\mathrm{a}}$ & $2.88 \pm 1.06^{\mathrm{a}}$ \\
\hline & \multicolumn{2}{|c|}{ Taste } & \multicolumn{2}{|c|}{ Flavor } \\
\hline & Acid & Sweet & Caprine & Cupuassu \\
\hline NY & $3.35 \pm 0.91^{\mathrm{a}}$ & $2.25 \pm 0.95^{\mathrm{a}}$ & $3.40 \pm 0.98^{\mathrm{a}}$ & $2.20 \pm 0.96^{\mathrm{b}}$ \\
\hline CY5 & $3.44 \pm 0.99^{\mathrm{a}}$ & $2.27 \pm 0.88^{\mathrm{a}}$ & $3.17 \pm 1.09^{\mathrm{ab}}$ & $2.68 \pm 1.05^{\mathrm{a}}$ \\
\hline CY7.5 & $3.42 \pm 0.97^{\mathrm{a}}$ & $2.20 \pm 0.87^{\mathrm{a}}$ & $3.24 \pm 1.00^{\mathrm{ab}}$ & $2.71 \pm 1.00^{\mathrm{a}}$ \\
\hline \multirow[t]{3}{*}{ CY10 } & $3.57 \pm 0.99^{\mathrm{a}}$ & $2.40 \pm 0.94^{\mathrm{a}}$ & $3.13 \pm 0.96^{\mathrm{b}}$ & $2.87 \pm 0.98^{\mathrm{a}}$ \\
\hline & \multicolumn{2}{|c|}{ Color } & \multicolumn{2}{|c|}{ Texture } \\
\hline & Whiteness & Yellowness & Consistency & Viscosity \\
\hline NY & $3.14 \pm 0.63^{\mathrm{a}}$ & $2.68 \pm 0.74^{\mathrm{b}}$ & $2.07 \pm 0.89^{\mathrm{b}}$ & $2.19 \pm 0.94^{\mathrm{b}}$ \\
\hline CY5 & $2.97 \pm 0.61^{\mathrm{a}}$ & $2.87 \pm 0.77^{\mathrm{ab}}$ & $2.20 \pm 0.85^{\mathrm{ab}}$ & $2.33 \pm 0.91^{\mathrm{ab}}$ \\
\hline CY7.5 & $2.98 \pm 0.59^{\mathrm{a}}$ & $2.96 \pm 0.71^{\mathrm{a}}$ & $2.35 \pm 0.87^{\mathrm{a}}$ & $2.47 \pm 0.96^{\mathrm{a}}$ \\
\hline CY10 & $2.98 \pm 0.68^{\mathrm{a}}$ & $2.97 \pm 0.80^{\mathrm{a}}$ & $2.41 \pm 0.86^{\mathrm{a}}$ & $2.41 \pm 0.83^{\mathrm{ab}}$ \\
\hline
\end{tabular}

consumer acceptance (Table 3). The parameters with a $>0.5$ penalty score and $>20 \%$ occurrence were considered detrimental attributes for overall acceptability. White- and yellow-colored attributes were not penalized in any treatment. However, all treatments were penalized by an excess of a caprine aroma, acid taste, and caprine flavor as well as by a lack of sweet taste, consistency, and viscosity. The yogurt samples containing cupuassu pulp (CY5, CY7.5, and CY10) were penalized by an excess of an acid aroma and alcoholic aroma and by a lack of cupuassu aroma and cupuassu flavor. Nevertheless, all attributes evaluated in this experiment were close to ideal (JAR ranging from 2.07 to 3.57) in all treatments.

Although the addition of cupuassu did not affect $(P$ $>0.05$ ) the acceptance attributes (appearance, color, aroma, flavor, texture, and overall acceptability) and purchase intention, cupuassu influenced $(P<0.05)$ some JAR attributes such as aroma, flavor, color, consistency, and viscosity. According to Jaeger et al. (2015), JAR questions can improve consumers' discrimination of samples based on hedonic scores because this type of questionnaire increases consumers' engagement. This fact may explain the differences found between formulations of JAR attributes related to acid, alcoholic and cupuassu aroma, cupuassu and caprine flavor, yellow color, consistency, and viscosity. Combining the data from JAR profiles and penalty analysis made it possible to identify the parameters for each treatment (NY, CY5, CY7.5, and CY10) that can be improved to increase consumer acceptance.

\section{Physicochemical Analyses}

The physicochemical parameters were evaluated with the aim of characterizing the new yogurt and correlating these parameters with sensory attributes (Table 4). The physicochemical results ( $\mathrm{pH}, \mathrm{TPC}$, color, apparent viscosity, and texture) are exhibited in Table 4.

Cupuassu formulations were characterized by lower $\mathrm{pH}$ and lightness but had greater TPC, redness, yellowness and apparent viscosity than NY $(P<0.05)$. Therefore, these parameters exhibited a significant relation with the cupuassu level (Table 4), presenting a direct (TPC, redness, yellowness, and apparent viscosity) and indirect ( $\mathrm{pH}$ and lightness) concentrationdependent influence. The $\mathrm{pH}$ of NY (4.65) is due to the fermentation of lactose to lactic acid, which decreases the $\mathrm{pH}$ of milk (Costa and Conte-Junior, 2015; Costa et al., 2016). In addition, the gradual decrease in $\mathrm{pH}$ of goat milk yogurt when cupuassu pulp was added can be related to the $\mathrm{pH}$ of cupuassu pulp (Costa et al., 2016), which averages 3.4 (Rogez et al., 2004). However, the addition of this fruit promoted an increase in TPC content of the final product, possibly resulting in the better antioxidant activity of the cupuassu goat milk 
Table 3. Consumer penalty analysis of the just-about-right (JAR) diagnostic attributes (percentage of consumers and mean decreases) ${ }^{1}$

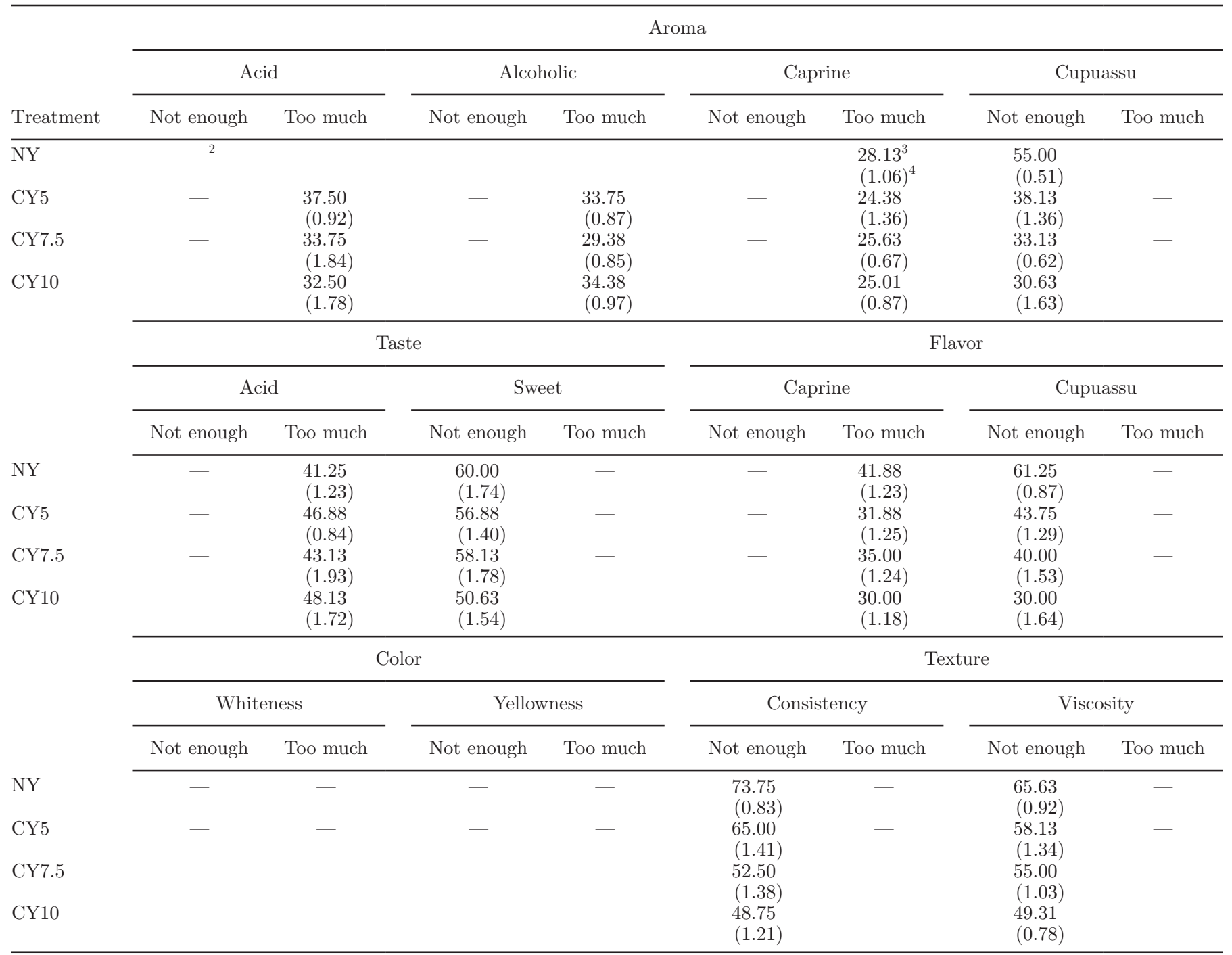

${ }^{1} \mathrm{NY}=$ natural goat milk yogurt; CY5 = cupuassu goat milk yogurt with 5.0\% pulp; CY7.5 = cupuassu goat milk yogurt with $7.5 \%$ pulp; CY10 $=$ cupuassu goat milk yogurt with $10.0 \%$ pulp.

${ }^{2}(-)$ indicates that less than $20 \%$ of consumers chose that JAR category.

${ }^{3}$ Upper number is the percentage of consumers who found treatments to be not enough or too much for JAR aroma, taste, flavor, color, and texture.

${ }^{4}$ The number in parentheses is the change in the mean compared with the consumer response score to overall acceptability.

yogurt, mainly in the CY10, because the cupuassu pulp is rich in phenolic compounds (Pugliese et al., 2013).

The white color of goat milk yogurt is due to the absence of $\beta$-carotene in goat milk, which is converted to vitamin A (Park et al., 2007). Thus, the different color values $\left(\mathrm{L}^{*}, \mathrm{a}^{*}\right.$, and $\left.\mathrm{b}^{*}\right)$ of cupuassu goat milk yogurts can be due to the distinctive color of cupuassu pulp, which is light yellow (Silva and Silva, 1999). The level of yellowness of the cupuassu goat milk yogurt depends on the type and concentration of fruit (Costa et al., 2015b), which may be influenced by the leakage of natural pigments, such as phenolic acids.
Furthermore, the addition of cupuassu pulp into goat milk yogurt increased the apparent viscosity. This is due to the particular chemical composition of this fruit pulp, which is rich in fibers and contains a considerable amount of starch as well as pectin polysaccharides (Vriesmann et al., 2009). Costa et al. (2015b) observed the same behavior in the instrumental physicochemical parameters of cupuassu goat milk yogurt. However, the cupuassu concentrations did not affect the instrumental texture (firmness, consistency, or cohesiveness; $P>$ 0.05) of the goat milk yogurt. This is because yogurt texture is highly dependent on the type of culture, TS, 
Table 4. Physicochemical parameters of cupuassu yogurts made from goat milk ${ }^{1}$

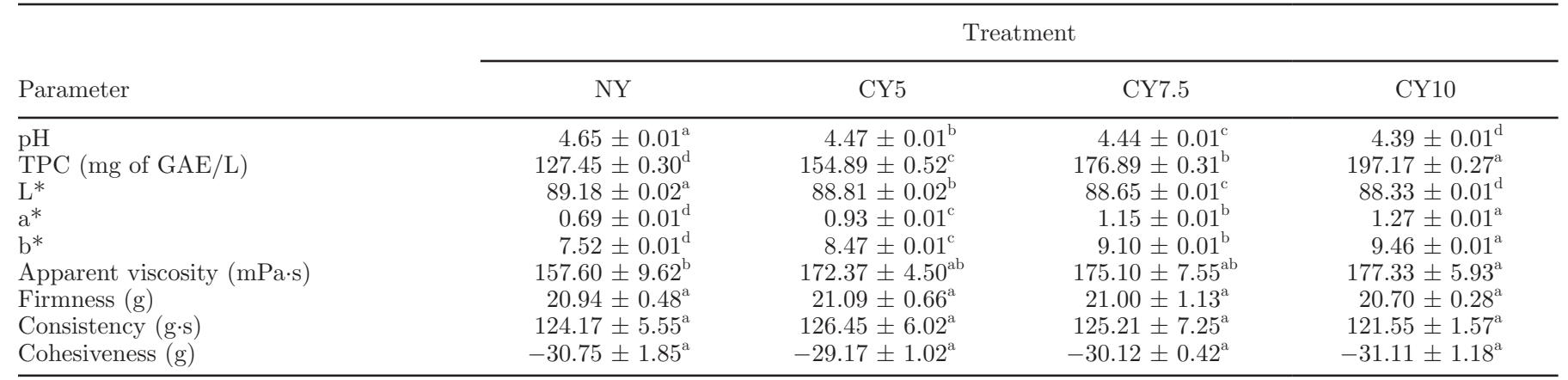

${ }^{\mathrm{a}-\mathrm{d}}$ Different lowercase letters in the same row represent significant differences $(P<0.05) ; \mathrm{n}=2$.

${ }^{1} \mathrm{TPC}=$ total phenolics content; GAE $=$ gallic acid equivalents; $\mathrm{L}^{*}=$ lightness; $\mathrm{a}^{*}=$ redness; and $\mathrm{b}^{*}=$ yellowness. $\mathrm{NY}=$ natural goat milk yogurt; CY5 = cupuassu goat milk yogurt with $5.0 \%$ pulp; CY7.5 = cupuassu goat milk yogurt with $7.5 \%$ pulp; CY10 = cupuassu goat milk yogurt with $10.0 \%$ pulp. Values were expressed as a mean $\pm \mathrm{SD}$.

and protein contents of the milk product (Costa et al., 2015b), which were the same composition in all treatments.

\section{PCA and PLSR}

The 2 principal components explained $89.39 \%$ of the observed variance (Figure 2). The first component (PCA1) was predominant and contributed a higher percentage of explained variance $(70.4 \%)$ than the second component (PCA2; 19.0\%). The PCA separated all treatments (NY, CY5, CY7.5, and CY10) into 2 groups based on sensory properties (aroma, taste, flavor, color, texture) and physicochemical parameters ( $\mathrm{pH}$, TPC, color, and apparent viscosity). The cupuassu goat milk yogurts (CY5, CY7.5, and CY10) can be identified by greater acid, alcoholic and cupuassu aromas, acid taste, cupuassu flavor, yellow color, consistency, and viscosity, TPC, redness, yellowness, and apparent viscosity. Nonetheless, cupuassu treatments were characterized by lower caprine aroma, caprine flavor, blackness of color, $\mathrm{pH}$, and lightness. In addition, PCA1 and PCA2 demonstrated that acid taste, cupuassu aroma, cupuassu flavor, yellow color, consistency, TPC, redness, and yellowness were more pronounced in CY10.

Cupuassu pulp has a specific chemical composition (Rogez et al., 2004) resulting in significant sensory changes, which were detected by PCA and JAR data in our study. Pearson correlation indicated that cupuassu pulp addition masked the caprine flavor, positively influencing the flavor of the new product. These results are corroborated by Senaka Ranadheera et al. (2012), which confirm that the addition of fruit pulp can mask the goat milk taste and improve the texture of goat milk yogurt. The flavor of goat milk yogurt is not accepted by nonhabitual consumers (Costa et al., 2014, 2015a). Similar to our findings, Senaka Ranadheera et al. (2012) and Mangia et al. (2014) observed that the addition of commercial fruit juice and myrtle berry juice masked the caprine flavor of the goat milk yogurt. Therefore, the addition of cupuassu pulp can be considered a new technology strategy to improve the perception of positive attributes of goat milk yogurts.

Partial least squares regression was used to determine the sensory attributes and physicochemical parameters, which contributed to overall acceptability (Figure 3). The PLSR model $\left(\mathrm{Q}^{2}=0.818\right)$ explained $95.0 \%$ of the overall acceptability by consumers (y-axis) and $99.4 \%$ of the hedonic scores and physicochemical parameters (x-axis). The sensory and physicochemical parameters were considered relevant when their respective "variable important to the projection" value was $>1.0$ (Wold et al., 2001). Aroma, flavor, texture, cupuassu aroma, acid taste, cupuassu flavor, yellow color, consistency, viscosity, TPC, redness, yellowness, and apparent viscosity positively contributed to the overall acceptability of the cupuassu goat milk yogurt. On the other hand, $\mathrm{pH}$ and lightness were considered detrimental parameters to overall acceptability. Regarding Pearson correlation, coefficients of a strong association were observed among sensory attributes and physicochemical parameters. The most important correlations were between flavor and caprine flavor $(\mathrm{r}=-0.850)$, cupuassu flavor and caprine flavor $(\mathrm{r}=-0.907)$, acid taste and cupuassu flavor $(\mathrm{r}=0.847)$, acid taste and $\mathrm{pH}(\mathrm{r}=-0.827)$, yellow color and lightness $(\mathrm{r}=-0.925)$, yellow color and redness $(\mathrm{r}=0.959)$, yellow color and yellowness $(\mathrm{r}$ $=0.977)$, sensory consistency and apparent viscosity ( $\mathrm{r}$ $=0.922)$, and sensory viscosity and apparent viscosity $(\mathrm{r}=0.919)$.

Analysis of variance analyses revealed that the cupuassu pulp addition increased the redness and yellowness while decreasing the lightness, which resulted in a more pronounced yellow color that positively con- 


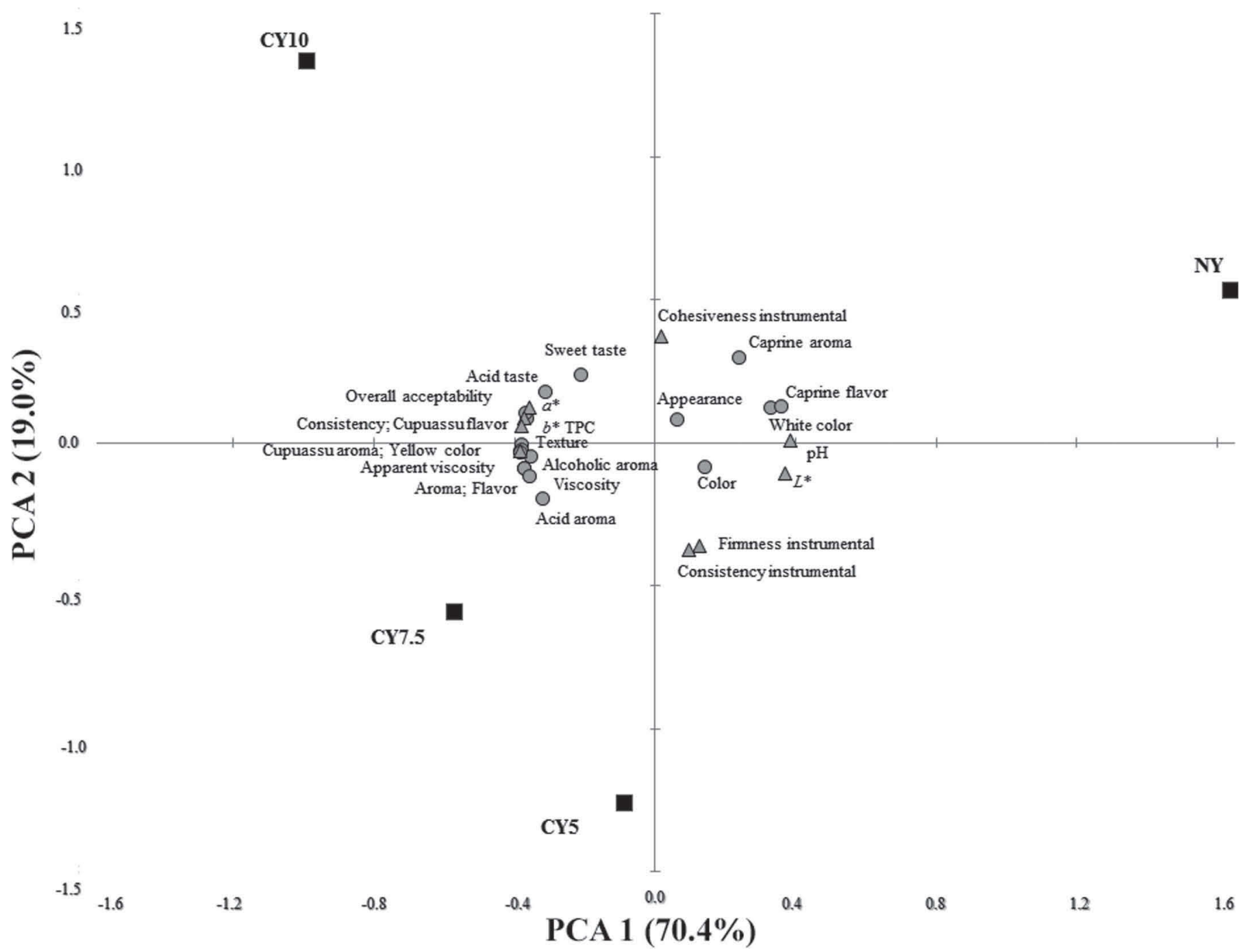

Figure 2. Physicochemical and sensory data of different formulations of cupuassu yogurts manufactured from goat milk in the plane defined by 2 principal components. The figure was scaled to show the subtleties of separation. PCA = principal component analysis; NY = natural goat milk yogurt; CY5 = goat milk yogurt with $5.0 \%$ cupuassu pulp; CY7.5 = goat milk yogurt with $7.5 \%$ cupuassu pulp; CY10 = goat milk yogurt with $10.0 \%$ cupuassu pulp; TPC $=$ total phenolics content; $L^{*}=$ lightness; $a^{*}=$ redness; and $b^{*}=$ yellowness.

tributed to overall acceptability by PLSR. Likewise, increased lightness can be detrimental to the acceptance of cupuassu goat milk yogurts. Furthermore, the cupuassu pulp increased the apparent viscosity, possibly leading to an increase in the sensory perception of the consistency and viscosity of ANOVA, which was positive for the overall linking taking into account the PLSR data. Food acceptance depends on the affinity between the food and the consumer. In this context, food characteristics such as flavor and physical structure can influence consumers' decisions to accept or reject a food. Nonetheless, the evidence regarding the influence of the food color on consumers' perception is ambiguous; whereas some studies have demonstrated a significant effect of the color on product acceptance, other experiments have not observed any effect of this parameter (Spence et al., 2010). Our results indicate that cupuassu pulp potentially affected the flavor, color, and texture of the goat milk yogurt.

Based on PCA, PLSR, JAR, and penalty analysis, cupuassu addition demonstrated a greater potential for improving some of the penalized attributes, such as caprine and cupuassu aroma, acid taste, caprine and cupuassu flavor, yellow color, consistency, and viscosity, which positively contributed to overall acceptability. To the best of our knowledge, no sensory studies are available regarding the addition of cupuassu pulp to goat milk yogurt, therefore, this study contributes to the scientific community with unpublished data. However, previous studies (Senaka Ranadheera et al., 2012; Man- 


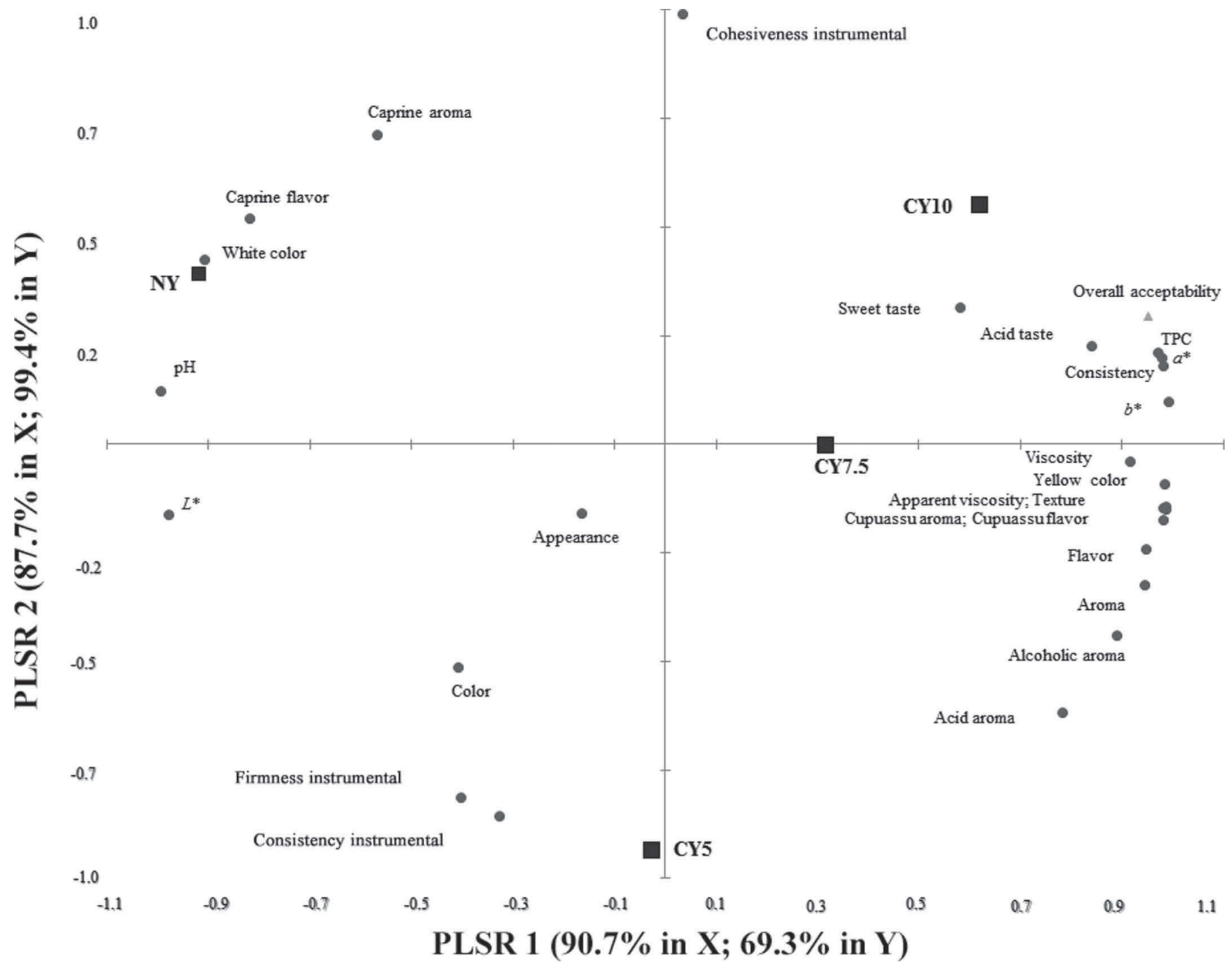

Figure 3. Partial least squares regression (PLSR) for sensory attributes and physicochemical parameters of different formulations of cupuassu yogurts made from goat milk. PLSR $1=$ physicochemical and sensory parameters; PLSR $2=$ overall acceptability. NY $=$ natural goat milk yogurt; CY5 = goat milk yogurt with $5.0 \%$ cupuassu pulp; CY7.5 = goat milk yogurt with $7.5 \%$ cupuassu pulp; CY10 = goat milk yogurt with $10.0 \%$ cupuassu pulp; TPC $=$ total phenolics content; $L^{*}=$ lightness; $a^{*}=$ redness; and $b^{*}=$ yellowness.

gia et al., 2014) confirm that the addition of fruit juice and syrup can improve the sensory characteristics of yogurt formulations made from goat milk.

\section{Antioxidant Health Information}

Yogurt consumption is recommended worldwide as part of a healthy diet, which makes this product a healthy food (Costa et al., 2013). Some studies show that consumers have a stronger preference for simple and well-known claims, such as probiotic and functional food (Lähteenmäki et al., 2010; Bitzios et al., 2011). Our study tested the effect of an unfamiliar claim (the benefits of antioxidants) related to the addition of cupuassu pulp by hedonic evaluation of yogurt samples (CY5, CY7.5, and CY10; Table 5). The health information increased the overall acceptability $\left[\mathrm{F}_{(0.08)}=14.95\right.$, $P<0.001 ; \mathrm{F}_{(0.17)}=32.44, P<0.001 ; \mathrm{F}_{(0.13)}=23.33$, $P<0.001]$, cupuassu flavor $\left[\mathrm{F}_{(0.08)}=14.95, P<0.001\right.$; $\left.\mathrm{F}_{(0.13)}=24.79, P<0.001 ; \mathrm{F}_{(0.11)}=19.95, P<0.001\right]$, and purchase intention $\left[\mathrm{F}_{(0.13)}=24.10, P<0.001 ; \mathrm{F}_{(0.15)}\right.$ $\left.=28.20, P<0.001 ; \mathrm{F}_{(0.18)}=34.38, P<0.001\right]$ in all treatments (CY5, CY7.5, and CY10). Therefore, the antioxidant health information improved $(P<0.05)$ the acceptance of cupuassu goat milk yogurt, indicating another advantage for the addition of cupuassu pulp. 
Table 5. Mean liking scores for the 3 treatments containing cupuassu pulp by the blind and informed groups $(\mathrm{n}=160)^{1}$

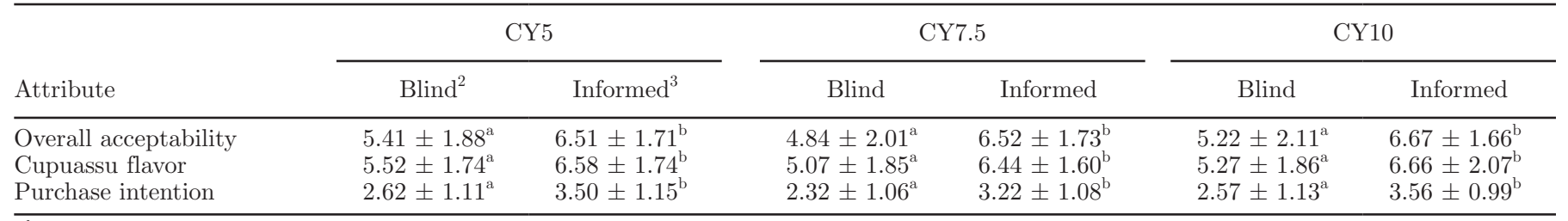

${ }^{\mathrm{a}, \mathrm{b}}$ Different lowercase letters on the same row represent significant differences $(P<0.001)$.

${ }^{1}$ Overall acceptability and cupuassu flavor attributes were evaluated in a structured 9-point hedonic scale, whereas purchase intention was evaluated in a structured 5-point hedonic scale. Values were expressed as a mean \pm SD. CY5 $=$ cupuassu goat milk yogurt with $5.0 \%$ pulp; CY7.5 $=$ cupuassu goat milk yogurt with $7.5 \%$ pulp; CY10 = cupuassu goat milk yogurt with $10.0 \%$ pulp.

${ }^{2}$ Blind: participants received the samples without information.

${ }^{3}$ Informed: participants received the samples with healthy information.

\section{CONCLUSIONS}

We conclude that in our study the expectations did not affect consumer acceptance. Nevertheless, the goat milk yogurts formulated with cupuassu pulp presented a favorable acceptance. Cupuassu pulp has potential as an ingredient in goat milk yogurt. In addition, the antioxidant health information increased the acceptance of cupuassu goat milk yogurts; cupuassu pulp can be used to enhance some attributes of goat milk yogurt. In this way, the addition of cupuassu pulp associated with the effect of health information can be successfully combined to increase acceptance of this dairy product. Furthermore, the goat milk yogurts containing $10 \% \mathrm{cu}-$ puassu pulp were considered the best formulation based on the parameters investigated in this study.

\section{ACKNOWLEDGMENTS}

The authors thank the Fundação de Amparo à Pesquisa do Estado do Rio de Janeiro (grant no. E-26/201.185/2014 and E-26/010.001.911/2015, FAPERJ, Brazil), Coordenação de Aperfeiçoamento de Pessoal de Nível Superior (process no. 125, CAPES/ Embrapa 2014, CAPES, Brazil), and the Conselho Nacional de Desenvolvimento Científico e Tecnológico (grant no. 311361/2013-7, CNPq, Brazil) for their financial support. The authors thank Anatole Ivanow (Centro Laboratorial Analitico, Universidade Federal Fluminese, Rio de Janeiro, Brazil) for the English revision of the manuscript.

\section{REFERENCES}

AOAC International. 2012. Official Methods of Analysis. 19th ed. AOAC Int., Arlington, VA.

Bitzios, M., I. Fraser, and J. Haddock-Fraser. 2011. Functional ingredients and food choice: Results from a dual-mode study employing means-end-chain analysis and a choice experiment. Food Policy 36:715-725. http://dx.doi.org/10.1016/j.foodpol.2011.06.004.
Costa, M. P., C. F. Balthazar, R. M. Franco, E. T. Mársico, A. G. Cruz, and C. A. Conte-Junior. 2014. Changes on expected taste perception of probiotic and conventional yogurts made from goat milk after rapidly repeated exposure. J. Dairy Sci. 97:2610-2618. http://dx.doi.org/10.3168/jds.2013-7617.

Costa, M. P., C. F. Balthazar, R. V. B. Pinto, A. G. Cruz, and C. A. Conte-Junior. 2013. Leite fermentado: potencial alimento funcional. Enciclopédia Biosfera 9:1387-1408.

Costa, M. P., and C. A. Conte-Junior. 2013. Leites fermentados como alimentos funcionais. Animal Business Brasil 3:60-65.

Costa, M. P., and C. A. Conte-Junior. 2015. Chromatographic methods for the determination of carbohydrates and organic acids in foods of animal origin. Comprehensive Reviews in Food Science and Food Safety 14:586-600.

Costa, M. P., C. F. Balthazar, B. L. Rodrigues, C. A. Lazaro, A. C. Silva, A. G. Cruz, and C. A. Conte-Junior. 2015a. Determination of biogenic amines by high-performance liquid chromatography (HPLC-DAD) in probiotic cow's and goat's fermented milks and acceptance. Food Sci. Nutr. 3:172-178. http://dx.doi.org/10.1002/ fsn 3.200 .

Costa, M. P., B. S. Frasao, B. R. C. Costa Lima, B. L. Rodrigues, and C. A. Conte-Junior. 2016. Simultaneous analysis of carbohydrates and organic acids by HPLC-DAD-RI for monitoring goat's milk yogurts fermentation. Talanta 152:162-170. http://dx.doi. org/10.1016/j.talanta.2016.01.061.

Costa, M. P., B. S. Frasao, A. C. O. Silva, M. Q. Freitas, R. M. Franco, and C. A. Conte-Junior. 2015b. Cupuassu (Theobroma grandiflorum) pulp, probiotic, and prebiotic: Influence on color, apparent viscosity, and texture of goat milk yogurts. J. Dairy Sci. 98:59956003. http://dx.doi.org/10.3168/jds.2015-9738.

Fernqvist, F., and L. Ekelund. 2014. Credence and the effect on consumer liking of food-A review. Food Qual. Prefer. 32:340-353. http://dx.doi.org/10.1016/j.foodqual.2013.10.005.

Hong, J. H., H. S. Park, S. J. Chung, L. Chung, S. M. Cha, S. Lê, and K. O. Kim. 2014. Effect of familiarity on a cross-cultural acceptance of a sweet ethnic food: A case study with Korean traditional cookie (Yackwa). J. Sens. Stud. 29:110-125. http://dx.doi. org/10.1111/joss.12087.

Jaeger, S. R., D. C. Hunter, K. Kam, M. K. Beresford, D. Jin, A. G. Paisley, S. L. Chheang, C. M. Roigard, and G. Ares. 2015. The concurrent use of JAR and CATA questions in hedonic scaling is unlikely to cause hedonic bias, but may increase product discrimination. Food Qual. Prefer. 44:70-74. http://dx.doi.org/10.1016/j. foodqual.2015.04.001.

Khan, R. S., J. Grigo, R. Winger, and A. Win. 2013. Functional food product development-Opportunities and challenges for food manufacturers. Trends Food Sci. Technol. 30:27-37. http://dx.doi. org/10.1016/j.tifs.2012.11.004.

Kim, M. J., and J. H. Hong. 2015. Do sensory constructs underlying a multidimensional sensory attribute moderate the effect of information on its perception? A case study of nuttiness in soymilk. Food Qual. Prefer. 40:87-96. http://dx.doi.org/10.1016/j. foodqual.2014.09.006. 
Kraus, A. 2015. Development of functional food with the participation of the consumer. Motivators for consumption of functional products. Int. J. Consum. Stud. 39:2-11. http://dx.doi.org/10.1111/ ijcs. 12144 .

Lähteenmäki, L., P. Lampila, K. Grunert, Y. Boztug, Ø. Ueland, A. Åström, and E. Martinsdóttir. 2010. Impact of health-related claims on the perception of other product attributes. Food Policy 35:230-239. http://dx.doi.org/10.1016/j.foodpol.2009.12.007.

Lampila, P., M. Van Lieshout, B. Gremmen, and L. Lähteenmäki. 2009. Consumer attitudes towards enhanced flavonoid content in fruit. Food Res. Int. 42:122-129. http://dx.doi.org/10.1016/j. foodres.2008.09.002.

Lawless, H. T., and H. Heymann. 2010. Principles of good practice. Page 72 in Sensory Evaluation of Food, 2nd ed. Springer, New York, NY.

Li, B., J. E. Hayes, and G. R. Ziegler. 2014. Just-about-right and ideal scaling provide similar insights into the influence of sensory attributes on liking. Food Qual. Prefer. 37:71-78.

Lobo, V., A. Patil, A. Phatak, and N. Chandra. 2010. Free radicals, antioxidants and functional foods: Impact on human health Pharmacogn. Rev. 4:118-126. http://dx.doi.org/10.4103/09737847.70902.

Mangia, N. P., M. A. Murgia, F. Fancello, A. Nudda, and P. Deiana. 2014. Influence of myrtle juice and syrup on microbiological, physicochemical, and sensory features of goat's milk yogurt made with indigenous starter culture. J. Microbial Biochem. Technol. 6:370-374. http://dx.doi.org/10.4172/1948-5948.1000171.

Park, Y. W., M. Juárez, M. Ramos, and G. F. W. Haenlein. 2007. Physico-chemical characteristics of goat and sheep milk. Small Rumin. Res. 68:88-113. http://dx.doi.org/10.1016/j. smallrumres.2006.09.013.

Pugliese, A. G., F. A. Tomas-Barberan, P. Truchado, and M. I. Genovese. 2013. Flavonoids, proanthocyanidins, vitamin C, and antioxidant activity of Theobroma grandiflorum (Cupuassu) pulp and seeds. J. Agric. Food Chem. 61:2720-2728. http://dx.doi. org/10.1021/jf304349u.

Ribeiro, A. C., and S. D. A. Ribeiro. 2010. Specialty products made from goat milk. Small Rumin. Res. 89:225-233. http://dx.doi. org/10.1016/j.smallrumres.2009.12.048.

Rogez, H., R. Buxant, E. Mignolet, J. N. S. Souza, E. M. Silva, and Y. Larondelle. 2004. Chemical composition of the pulp of three typical Amazonian fruits: Araça-boi (Eugenia stipitata), bacuri (Platonia insignis) and cupuaçu (Theobroma grandiflorum). Eur. Food Res. Technol. 218:380-384. http://dx.doi.org/10.1007/s00217-0030853-6.

Salgado, J. M., B. S. Rodrigues, C. M. Donado-Pestana, C. T. S. Dias, and M. C. Morzelle. 2011. Cupuassu (Theobroma grandiflorum) peel as potential source of dietary fiber and phytochemicals in whole-bread preparations. Plant Foods Hum. Nutr. 66:384-390. http://dx.doi.org/10.1007/s11130-011-0254-0.

Senaka Ranadheera, C., C. A. Evans, M. C. Adams, and S. K. Baines. 2012. Probiotic viability and physico-chemical and sensory properties of plain and stirred fruit yogurts made from goat's milk. Food Chem. 135:1411-1418. http://dx.doi.org/10.1016/j. foodchem.2012.06.025

Silva, F. M., and C. L. M. Silva. 1999. Colour changes in thermally processed cupuaç (Theobroma grandiflorum) puree: critical times and kinetics modelling. Int. J. Food Sci. Technol. 34:87-94. http:// dx.doi.org/10.1046/j.1365-2621.1999.00246.x.

Silva Pinto, M., F. M. Lajolo, and M. I. Genovese. 2008. Bioactive compounds and quantification of total ellagic acid in strawberries (Fragaria x ananassa Duch.). Food Chem. 107:1629-1635. http:// dx.doi.org/10.1016/j.foodchem.2007.10.038.

Singleton, V. L., and J. A. Rossi. 1965. Colorimetry of total phenolics with phosphomolybdic-phosphotungstic acid reagents. Am. J. Enol. Vitic. 16:144-158.

Spence, C., C. Levitan, M. U. Shankar, and M. Zampini. 2010. Does food color influence taste and flavor perception in humans? Chemosens. Percept. 3:68-84. http://dx.doi.org/10.1007/s12078-0109067-z.

Tuorila, H. M., H. L. Meiselman, A. V. Cardello, and L. L. Lesher. 1998. Effect of expectations and the definition of product category on the acceptance of unfamiliar foods. Food Qual. Prefer. 9:421430. http://dx.doi.org/10.1016/S0950-3293(98)00012-3.

Vidigal, M. C., V. P. Minim, N. B. Carvalho, M. P. Milagres, and A. C. Gonçalves. 2011. Effect of a health claim on consumer acceptance of exotic Brazilian fruit juices: Acaí (Euterpe oleracea Mart.), Camu-camu (Myrciaria dubia), Cajá (Spondias lutea L.) and Umbu (Spondias tuberosa Arruda). Food Res. Int. 44:19881996. http://dx.doi.org/10.1016/j.foodres.2010.11.028.

Villegas, B., I. Carbonell, and E. Costell. 2008. Effects of product information and consumer attitudes on responses to milk and soybean vanilla beverages. J. Sci. Food Agric. 88:2426-2434. http:// dx.doi.org/10.1002/jsfa.3347.

Vriesmann, L. C., J. L. M. Silveira, and C. L. O. Petkowicz. 2009. Chemical and rheological properties of a starch-rich fraction from the pulp of the fruit cupuassu (Theobroma grandiflorum). Mater. Sci. Eng. 29:651-656. http://dx.doi.org/10.1016/j msec.2008.12.011.

Wold, S., M. Sjöström, and L. Eriksson. 2001. PLS-regression: A basic tool of chemometrics. Chemometr. Intell. Lab. 58:109-130. http:// dx.doi.org/10.1016/S0169-7439(01)00155-1.

Zhao, B. 2009. Natural antioxidants protect neurons in Alzheimer's disease and Parkinson's disease. Neurochem. Res. 34:630-638. http://dx.doi.org/10.1007/s11064-008-9900-9. 